\title{
Un acercamiento etnográfico a una ciudad otomana de finales del siglo XVIII. El Viage a Esmirna de Pedro María González
}

\author{
Guillermo Olagüe de Ros (*) \\ (*) Departamento de Historia de la Ciencia. Universidad de Granada. \\ golague@ugr.es
}

SUMARIO: 1.—Introducción. 1.1.—Pedro María González y su Viage a Esmirna. 2.—La imagen del turco en la literatura europea de los siglos XVII y XVIII. 3.- La contribución de Pedro María González al conocimiento del turco: entre el saber libresco y un atento empirismo. 4.-Conclusión.

RESUMEN: Pedro María González, un cirujano formado en el Colegio de Cádiz, participó en el verano de 1796 en la expedición fletada por el Consulado de Cádiz y que tenía por objeto iniciar relaciones comerciales con Esmirna, la más importante ciudad comercial del Imperio Otomano. A su regreso redactó un texto con el fin de facilitar a otros españoles futuras empresas comerciales, además de mostrar detalladamente los hábitos y costumbres de los diferentes grupos que habitaban en esa ciudad. En este artículo analizo la visión que los europeos de esa época tenían de los osmanlíes, y las razones ideológicas y conceptuales de su negativa opinión, para a continuación mostrar la del propio González, especialmente la de los judíos, el grupo étnico que mejor estudió. No cabe duda de que un idioma común, el castellano, facilitó sus relaciones y su cuidadoso análisis.

PALABRAS CLAVE: Pedro María González, relaciones España y Turquía, siglo XVIII, antropología cultural, Esmirna, sefardíes.

KEY WORDS: Pedro María González, relations between Spain and Turkey, XVIIIth century, cultural anthropology, Smyrna, Sephardim.

\section{Introducción}

Tras siglos de conflictos con los turcos y de vivir de espaldas a su extenso Imperio, en septiembre de 1782 España firmaba con Estambul un Tratado de Paz y de Comercio que, entre otras cláusulas, contemplaba un intercambio 
de embajadores y la posibilidad de que navíos españoles, que hasta entonces habían hecho la carrera de Indias, pudieran entablar tratos comerciales con las principales escalas de Levante. Entre 1784 y 1788 por lo menos en diez ocasiones buques españoles se trasladaron a la antigua Constantinopla para cumplir con el primer cometido del acuerdo. Años después, en el verano de 1796 la fragata La Experiencia, fletada por el Consulado de Cádiz y cargada de productos americanos, emprendía viaje a Esmirna, la capital mercantil del Imperio.

\subsection{Pedro María González y su Viage a Esmirna}

A bordo de dicha nave iba en calidad de naturalista Pedro María González, un cirujano formado en el Colegio de Cádiz y con amplia experiencia en misiones de este tipo. En efecto, también en calidad de cirujano había formado parte de la tripulación de La Atrevida, una de las dos naves que comandadas por Alejandro Malaspina (1754-1810) circunnavegó el globo terráqueo entre 1789 y 1794. En esta expedición González también tuvo un destacado papel como naturalista y recogió algunos datos sobre hábitos y costumbres de los habitantes de los lugares que visitaba. De regreso a España recibió el encargo, junto con su compañero Francisco de Flores Moreno (n. 1760), de escribir un texto sobre las enfermedades de la marinería, en el que debían plasmar sus experiencias durante los años de embarque en la escuadra de Malaspina. La redacción del mismo la alternó con algunos destinos como Protomédico y Cirujano Mayor de la flota, primeramente en una expedición a Argel. El Tratado de las enfermedades de la gente de mar, el resultado del encargo, es el texto más importante sobre esta materia publicado en castellano. Apareció con su única firma en 1805, varios años después de que se le confiara su confección, entre otras razones porque su participación en la expedición del Consulado gaditano le obligó a suspender la redacción del mismo. Tras revalidarse y doctorarse en Cirugía Médica y Medicina en 1799, en 1801 obtuvo la cátedra sustituta que desempeñaba su compañero Flores Moreno. En mayo de 1804 ascendió a la categoría de Maestro Consultor por haber concluido la redacción del Tratado. Ese mismo año fue nombrado catedrático en propiedad de Fisiología e Higiene del Colegio andaluz. Encargado de las salas del Hospital de Marina en Cádiz, vivió las consecuencias del combate de Trafalgar, el sitio 
francés durante la Guerra de la Independencia y las sucesivas epidemias de fiebre amarilla que azotaron a esa capital andaluza.

Además de este Tratado González fue autor, precisamente, de una Disertación médica sobre la calentura maligna contagiosa que reinó en Cádiz en 1800 (Cádiz, Imprenta de Manuel Ximénez Carreño, 1801) ${ }^{1}$, y un Discurso inaugural para la abertura de estudios del Real Colegio de Medicina y Cirugía de Cádiz... de 1814 (Cádiz, Impr. de Niel, 1814)². En la hoja de servicios de González, fechada en 1835 y redactada por Flores Moreno - director del Colegio gaditano en ese momento-, se le atribuye la publicación de una traducción española de las Observations sur les affections catharrales (París, 1807) de Pierre Jean Georges Cabanis (1757-1808), y de uno de los tratados de Antoine Germain Labarraque (1777-1850) sobre el uso de los cloruros como desinfectantes $(1828)^{3}$.

Por razones que he tratado en otro lugar, la permanencia de los gaditanos en Esmirna se demoró casi por dos años ${ }^{4}$. González recibió de los cónsules el encargo de redactar un tratado en el que expusiera los medios para facilitar las relaciones comerciales de otros españoles con las ciudades mercantiles otomanas. Como a juicio del sevillano apenas se disponía en castellano de buenos textos que abordaran la vida de los turcos, González recopiló abundantes noticias sobre los mismos, y las enriqueció con las que obtuvo tras la lectura de los libros más influyentes de su tiempo. El resultado final fue la redacción de dos gruesos volúmenes, el primero con noticias etnográficas y el segundo con útiles consejos de tipo comercial. Si

1. Este texto se tradujo al alemán en 1805 con el título Ueber das gelbe Fieber, welche 1800 in Cadiz herrschte. Aus dem Spanischen übersetz von Dr. W. H. L. Borges (Berlín, H. Frölich).

2. El tema de este discurso es: Importancia y noble objeto del arte de curar.

3. Expediente personal de Pedro María González. Archivo Histórico de Marina (en adelante AHM), Sanidad, leg. 2898. No he localizado ejemplar de la traducción castellana del texto de Cabanis, que según la hoja de servicios de González se editó en la Imprenta Real en Madrid. Más información sobre González, y en particular acerca de su participación en la expedición Malaspina en: Astrain Gallart, Mikel. Dos cirujanos andaluces con vocación de naturalistas en la expedición Malaspina: Pedro María González Gutiérrez (1760-1839) y Francisco de Flores Moreno (n. 1760). In: Carrillo, J. L.; Olagüe de Ros, G., eds. Actas del XXXIII Congreso Internacional de Historia de la Medicina. Sevilla: Imprenta A. Pinelo; 1994, p. 71-82. En una circunstancia González evocó en este viaje oriental su anterior experiencia como cirujano de la fragata La Atrevida, al comparar la costumbre de las judías de Esmirna de ensartar perlas en el peinado con las criollas de Lima.

4. Olagüe de Ros, Guillermo. Descubriendo la Sublime Puerta Otomana. El «Viage a Esmirna» (1796-ca. 1796) del sevillano Pedro María González (1760-1838). Granada: Editorial de la Universidad/«El Legado Andalusí» (en prensa). 
bien realizó gestiones para su publicación lo cierto es que su esfuerzo fue en vano, pues los dos tomos de su Viage a Esmirna permanecieron manuscritos, y se conservan en la actualidad en el Archivo del Museo Naval de Madrid ${ }^{5}$. En este trabajo analizo las consideraciones etnográficas que González plasmó en este primer volumen sobre los diferentes millets, o grupos confesionales de Esmirna, con especial atención al hebreo, al que conoció más directamente, en parte porque pudo comunicarse mejor con ellos al tener una lengua común: el castellano. Los otros millets - los armenios o persas, los griegos y los yourouk - son descritos muy librescamente, y de ellos no ofrece excesivas notas originales.

\section{La imagen del turco en la literatura europea de los siglos XVII y XVIII}

Al caracterizar los diferentes grupos que habitaban el Imperio Otomano los viajeros y analistas europeos occidentales del Antiguo Régimen adoptaron mayoritariamente una actitud francamente negativa, lo que les mermó finura en la observación ${ }^{6}$.

La barrera idiomática fue, no cabe duda, un elemento que dificultó la comunicación, salvo con los francos, los ciudadanos de la Europa occidental, aunque bien es cierto que siempre se podía contar con un dragomán para que sirviera de intérprete. Había que dar forma corpórea a quienes se visitaba, muchos de los cuales además eran reacios a entrar en contacto con los extranjeros. Por ello, como mostraré ahora, en las descripciones y en las caracterizaciones de esos pueblos la curiosidad, el exotismo y también la incomprensión, fueron las notas dominantes. Como muy plásticamente ha manifestado Çirakman «los europeos sabían de antemano lo que iban a ver» ${ }^{7}$.

5. González, Pedro María. Viage a Esmirna. 2 vols. (ms.) (1796-ca. 1798). Archivo del Museo Naval, Madrid, Ms-524-525.

6. «La ignorancia de los turcos, una de cuyas causas es la extrema dificultad de su idioma, les impide aproximarse más a la moral». Irumberry, Charles-Marie de. Voyage à Constantinople. Paris: Imprimerie de Crapelet; 1798, p. 152.

7. Çirakman, Asli. From Tyranny to Despotism: The Enlightenment's Unenlightened Image of the Turks. Int. J. Middle East Stud. 2001; 33: p. 60. González expresó muy claramente la actitud primeriza de un europeo que se encontraba con un abanico de desconocidos en todos los 
Cornelis de Bruyn (1652-1727) fue, sin duda, quien más claramente expuso el conflicto que suponía la imposibilidad de conversar con los turcos para retratarlos de una manera fundada. Ante este contratiempo, las opiniones de otros viajeros que habían podido hablar con los osmanlíes eran una fuente de información básica. El notable botánico francés Joseph Pitton de Tournefort (1656-1708), que sirvió de guía intelectual a otros viajeros en los dominios turcos, reconoció claramente su profundo desconocimiento del árabe y, a pesar de ello, estimó que El Corán era «un libro mal compuesto, que entre algunas cosas buenas contiene una infinidad de historias pueriles y frívolas» ${ }^{8}$. Paul Rycaut (1629-1700) fue, precisamente, quien primero elaboró una teoría aclaratoria del modo de ser de los turcos que, enriquecida con aportaciones posteriores, como la de Montesquieu, se convirtió en la dominante a lo largo de estos años y que, obviamente, también utilizó Pedro María González ${ }^{9}$. En el último cuarto de la centuria ilustrada el húngaro François Baron de Tott (1733-1793), que también llegó a dominar la lengua turca, se convirtió en el inspirador de muchos de los juicios vertidos a fines de ese siglo por diversos viajeros ${ }^{10}$.

La mayoría de los visitantes de la Sublime Puerta recalcaron la indolencia, poca laboriosidad, apatía y resignación de los turcos. Guillaume-Joseph Grelot (fl. 1680), por ejemplo, al comparar el amor al trabajo de los franceses con la parsimonia de los turcos, concluyó que éstos eran «indignos». Trabajaban cuando tenían necesidad, escribe, pero «como se contentan con muy poca cosa, no se esfuerzan»; además carecen de sensibilidad por «las artes e inclinación por las ciencias», por eso se habían visto obligados a dedicarse a oficios artesanales ${ }^{11}$. Según Tournefort «los musulmanes

ámbitos: «Los trajes Europeos es lo único que encuentra conforme a sus ideas». González, n. 5, vol. l, p. 110.

8. Tournefort, Joseph Pitton de. Relation d'un Voyage du Levant, fait par ordre du Roy. Vol. II, Paris: Imprimerie Royale; 1717, p. 56.

9. Bruyn, Cornelis de. Voyage en Levant. Traduit du flamand. Vol. I, Delft: Henri de Kroonenvelt; 1700, p. 77.

10. «Puesto que el conocimiento de la lengua turca era la única manera que tenía para hacerme con las maneras y costumbres de esta nación, mi primer objetivo fue aprenderla». Baron de Tott, François. Memoirs. The second edition to which are subjoined, The strictures of $M$. Peyssonnel. Translated form the French in two volumes. $2^{\text {a }}$ ed., vol. I, London: G. G. J. and J. Robinson; 1786, p. 7-9. Baron de Tott atribuía la ignorancia de los turcos en las ciencias precisamente a la gran complejidad de su idioma.

11. «No hay que asombrarse si sólo se encuentra entre ellos lo que es absolutamente para vivir (...) son pues gentes tan groseras y poco estudiosas como en general los mahometanos». 
pasaban la vida ociosamente, comiendo arroz, bebiendo agua, fumando tabaco, o tomando café» ${ }^{12}$. El tiempo no pasaba por los otomanos que, impasiblemente, vivían fosilizados. Charles Mac Farlane (m. 1858) trabó un primer conocimiento del mundo osmanlí en 1827 y plasmó su experiencia en una obra sumamente interesante, Constantinople in 1828. Veinte años después volvió a Esmirna y se sintió profundamente decepcionado, pues confiaba en esta segunda visita que las pautas culturales de los europeos occidentales, muy ligadas a la actividad comercial de los francos, hubieran incrementado el nivel de civilización de los turcos. Pero no, según Mac Farlane el tiempo se había parado para Esmirna y sus ciudadanos. Desde el mismo momento en que divisó la ciudad desde la bahía percibió que aquella era idéntica a la que había dejado tiempo atrás. Una anécdota que relata en la crónica de esta segunda visita, expresa muy bien su decepción ante el inmovilismo de la ciudad. Un día acudió a una tienda del bazar y le atendió un turco que ya lo había hecho en 1827:

«Lo encontré sentado con las piernas cruzadas en el mismo lugar, en el mismo rincón, y en el mismo punto que cuando lo vi por primera vez veinte años atrás. Parecía como si nunca se hubiera movido de su sitio desde entonces, pero era más viejo y con el cabello gris» ${ }^{13}$.

Una de las cuestiones que los occidentales se plantearon fue, precisamente, la razón de esa falta de laboriosidad de los osmanlíes y de su resignación ante la realidad, que explicaron por causa del clima y sobre la base de la doctrina de la predestinación, razones que, a su vez, daban cuenta del modo de gobierno de la Sublime Puerta, un absolutismo extremadamente cruel. Prácticamente, en todos los autores hubo consenso en considerar despótica la forma de gobierno de Estambul. El despotismo turco no estaba sometido a la ley, pues lo arbitrario estaba por encima

Grelot, Guillaume-Joseph. Relation Nouvelle d'un Voyage de Constantinople. Paris: Pierre Rocolet; 1680, p. 300-301. Este modo de juzgar al turco sobre la base de estereotipos más o menos fundados fue el mismo al que recurrió, por ejemplo, Montesquieu para ridiculizar a los españoles en su Carta LXVIII, fechada en París en 1715. Cartas Persianas. Tomo I. Cádiz: Librería de Ortal y Compañía; 1821, p. 254-260.

12. Tournefort. n. 8, vol. I, p. 19.

13. Mac Farlane, Charles. Turkey and its destiny. Vol. I, Philadelphia: Lea and Blanchard; 1850, p. 24. 
de la razón ${ }^{14}$. Lo que diferenciaba políticamente el absolutismo oriental del de las potencias occidentales era su carácter caprichoso, dependiente exclusivamente de una persona, el Sultán, que gobernaba por el terror y el miedo que infundía en sus vasallos, mientras que en occidente los Estados Absolutos estaban sujetos a las leyes y al imperio de la razón. Puesto que los tres poderes - judicial, legislativo y ejecutivo- están «reunidos en el Sultán, reina el más horroroso despotismo» ${ }^{15}$. Los monarcas occidentales procuraban el bienestar de su pueblo, mientras que el Sultán turco era profundamente injusto, poco interesado en la felicidad de sus gentes y rodeado de una clase aristocrática y dirigente corrupta e inepta. González también se percató de esta estructura jerárquica y piramidal del gobierno turco que carecía de una base que asesorara y sostuviera la política del Sultán ${ }^{16}$.

Por su parte, el clima caluroso, propio de los países orientales, incitaba a la apatía y a la indiferencia. En lugares con altas temperaturas las personas eran fácilmente esclavizadas, mientras que en las más frías luchaban por su libertad. El clima, además, frenaba cualquier posibilidad de cambio. Por ello, Asia era débil mientras que Europa era fuerte ${ }^{17}$. Fueron, precisamente, Paul Rycaut ${ }^{18}$ y Charles Louis de Secondat (1689-1755), barón de Montesquieu, ya en la Ilustración, los dos autores que más relacionaron despotismo con el clima y las creencias religiosas ${ }^{19}$.

El otro elemento que a juicio de muchos viajeros explicaba el modo de ser de los osmanlíes era de contenido religioso. La mencionada doctrina de la predestinación era la que revelaba «el coraje de los turcos en el combate, y su paciencia ante la adversidad» ${ }^{20}$. Para Antoine-Laurent Castellan (1772-1838) era una creencia supersticiosa que expresaba en buena

14. William Eton basó en la religión la ineptitud de los osmanlíes para las ciencias y las artes. Eton, William. A survey of the Turkish empire. Vol. I, London: T. Cadell jun. and W. Davies; 1798, p. 194-195.

15. Secondat, Charles Louis de (barón de Montesquieu). Del Espíritu de las leyes. Tomo I, MadridLondres: Rosa; 1821, p. 240.

16. González, n. 5, vol. I, p. 148-149.

17. Çirakman, n. 7, p. 57-58.

18. Esa visión despótica y opresora de la Sublime Puerta está ya claramente manifiesta en The epistle to the reader de Paul Rycaut. Rycaut, Paul. The history of the present state of the Ottoman Empire. $5^{\text {a }}$ ed., London: T. N. for John Starkey; 1682 (1a ed.: 1655).

19. En su escrito citado en n. 16, Montesquieu elaboró extensamente su propia doctrina. Tomo I, p. 354-377; y Tomo II, p. 1-226.

20. De la Porte, Joseph. Le voyageur françois, ou La connaissance de l'ancien et du nouveau monde. Tomo I, Paris: Chez Vincent ; 1765, p. 66. 
medida ciertos comportamientos, como el valor heroico o la resignación. Pues si todo es por voluntad divina, el hombre debía de aceptar lo que le acontecía sin queja ${ }^{21}$.

Estas teorías acerca del modo de ser de los osmanlíes fueron las más generalizadas durante este período. Incluso, se enriquecieron con matices sumamente interesantes ${ }^{22}$. De la Porte, por ejemplo, formuló que aun siendo el clima una razón de ser importante en el modo de ser del turco, éste no afectaba por igual a todos. Así, los osmanlíes «europeos» eran «trabajadores, mañosos, esforzados», mientras que los «asiáticos» eran, por el contrario, «perezosos, flojos, afeminados» ${ }^{23}$.

Es decir, los turcos europeos eran, por tanto, los descendientes del glorioso Imperio Bizantino, que había sido destruido tras la llegada de un pueblo asiático, inculto e incivilizado. Un pueblo que De la Porte caracterizó como «fastuoso, duro, avaro, hipócrita, disimulado, tan dado al vicio de la incontinencia que las mujeres, aunque tengan varias, nunca bastan para darles siempre los placeres que buscan» ${ }^{24}$. De Constantinopla, que era geográficamente el último territorio de Occidente, se pasaba por un puente a Gálata y Pera, en la parte asiática, habitual residencia de los francos y extranjeros de la ciudad; la diferencia climatológica entre ambas orillas no debía de ser muy grande, obviamente, pero a pesar de ello, De la Porte marcó esa sutil diferencia, que subrayaba su visión peyorativa sobre el mundo turco.

21. Castellan, Antoine Laurent. Lettres sur la Morée, I'Hellespont et Constantinople. $2^{2}$ ed., vol. 2, Paris: A. Nepveu; 1820, p. 288-290.

22. Moreno, José. Viage á Constantinopla, en el año de 1784 escrita de orden superior. Madrid: Imprenta Real; 1790, p. 69: «La naturaleza y el clima los hacen blandos; sus creencias prevenidos; la costumbre del Oriente supersticiosos. De la combinación de estos tres principios resultan todas las prendas o tachas que en ellos se conocen. Gravedad, nobleza de corazón, indolencia genial, orgullo, potencias de mejor disposición que cultura, reserva sin cavilosidad, ciega sumisión a cuanto dimana del cielo o del trono, nimia credulidad, fanatismo, repugnancia invencible a cosas nuevas, ferocidad o abatimiento por extremos, firmeza en la amistad». Por su parte, Solano Ortiz de Rozas se expresó así: «Son generalmente robustos, de mucha talla, y hermosa presencia; se aplican poco al trabajo, pero ¿para qué buscar la razón de esto en la naturaleza o influencia del clima, quando la falta de industria y aplicación a las ciencias y artes, es efecto muy preciso de la constitución del despotismo que establece su poder sobre la ignorancia, y ninguna civilización de sus infelices vasallos?». Solano Ortiz de Rozas, José. Idea del Imperio Otomano. Madrid: Imprenta de Sancha; 1793, p. 75.

23. De la Porte, n. 20, p. 39

24. De la Porte, n. 20, p. 39-40. 
Baron de Tott «el más leal seguidor de la doctrina de Montesquieu acerca del despotismo otomano» 25 , afirmó que la arbitrariedad era un rasgo sustancial de los turcos. Según él el clima no era el único factor determinante en su forma de ser. Hay gobiernos despóticos y tiranos tanto en zonas gélidas como en lugares tórridos. Los individuos se resienten más por la forma de gobierno que tienen que por las causas de tipo físico. Las razones psicológicas, las morales y las creencias dominaban sobre las físicas. La tendencia de los turcos a la violencia y a la crueldad dependía más de la tiranía a que les tenían sometidos sus gobernantes que a cualquier otra consideración. Por tanto, las explosiones de ira del turco de la calle eran la respuesta a la tiranía a la que estaba sometido por sus gobernantes ${ }^{26}$.

Pero no todos los europeos mantuvieron estas tesis. Charles de Peyssonel, Ignatius Mouradgea d'Ohsson y John Cam Hobhouse fueron quizás, los que más claramente rompieron con estas imágenes estereotipadas acerca de los turcos ${ }^{27}$. Los dos primeros se esforzaron en demostrar la legalidad de su sistema político, por tanto su falta de arbitrariedad, y el tercero en aclarar que ciertas prácticas culturales, hasta entonces tenidas como propias de los osmanlíes y de los pueblos orientales, eran ya conocidas y cultivadas en la antigüedad clásica grecolatina.

Charles de Peyssonel (1727-1790) sucedió a su padre como cónsul de Francia en Esmirna, y era un buen conocedor del mundo oriental que analizó en varias obras impresas. Considerando que la obra de Baron de Tott contenía muchos errores escribió un texto, «Notas», que son abundantes y extensas rectificaciones al escrito del húngaro ${ }^{28}$. La tesis defendida por el francés fue, al igual que en Mouradgea d'Ohsson, que el gobierno otomano no era arbitrario, como comúnmente se pensaba; por el contrario se sustentaba, como en los países occidentales, en un entramado jurídico sólido y eficaz. Precisamente, por funcionar conforme a estrictas leyes. La

\footnotetext{
25. Çirakman, n. 8, p. 60

26. «Si el clima relaja las fibras de los turcos, el despotismo que les esclaviza les incita a la violencia (...) y esta ferocidad se incrementa con su doctrina de la Predestinación». Baron de Tott, n. 10, vol. I, p. VII.

27. El español José Moreno cita elogiosamente a Charles de Peyssonel y Mouradgea d'Ohsson, pues los considera unos muy buenos conocedores del país y de sus habitantes. Discrepa de Baron de Tott, al que reprocha su permanente deseo de ridiculizar a los turcos, pero no de Lady Mary Wortley Montagu, de la que considera que en sus cartas «reina la pasión de referir cosas muy ponderadas». Moreno, n. 22, p. 68-69.

28. De Peyssonel, Charles Strictires (sic) and remarks on the preceding memoirs by... In a Letter to the Marquis de N. In: Baron de Tott, n. 10, vol. II, p. 161-287.
} 
Sublime Puerta no podía calificarse desde el punto de vista político como despótica. Es más, afirmaba Peyssonel que el sistema osmanlí era mucho más tolerante y condescendiente que el de cualquier país, pues tanto a sus ciudadanos como a los comerciantes extranjeros apenas les gravaba con impuestos ${ }^{29}$. Además, Peyssonel fue un ardiente defensor de la política turca frente al creciente peso de la Rusia zarista y en prácticamente todos sus escritos defendió esta tesis ${ }^{30}$.

Ignatius Mouradgea d'Ohsson (1740-1807), Muradcan Tosunyan, dragomán de la Embajada de Suecia en Estambul, era armenio de religión católica, hijo de una francesa de Esmirna y de un traductor que trabajaba para dicha legación diplomática en la capital del Imperio. Educado exquisitamente viajó ampliamente por Europa. Y en Francia permaneció durante varios años. Fruto del profundo conocimiento que tenía de su país es su impresionante Tableau général de l'Empire Othoman, editado en Francia en tres volúmenes en folio (1787-1820), cuyo texto se acompañaba de una magnífica iconografía ${ }^{31}$. D'Ohsson defendió también que la Sublime Puerta era un estado regido por la ley. El actual declive del Imperio no respondía a que estuviera sumido en la anarquía, sino al anquilosamiento de su sistema de enseñanza y a la carencia de una tecnología adecuada a las necesidades de la época. La presencia de instituciones educativas conforme a patrones europeos y de asesores occidentales contratados para mejorar las infraestructuras básicas y las defensas del Imperio, eran la única alternativa. Findley ha querido ver en el Tableau, además, una clara respuesta al Voyage Pittoresque de la Grèce de Marie Gabriel Florent Auguste de Choiseul-Gouffier (1752-1817), una significada figura del prohelenismo de su tiempo y, por tanto, con escasas simpatías hacia el mundo otomano. Las figuras que aparecen en el frontispicio de estas dos obras muestran claramente las dispares posiciones de sus autores: Si en Choiseul-Gouffier Grecia, representada por la figura de

29. Thomson, Ann. L'Europe des Lumières et le monde musulman. Une altérité ambiguë. Cromhos. 2005; 10: 1-11.

30. Una nota biográfica sobre los Peyssonel en: BIOGRAPHIE Universelle (Michaud) Ancienne et Moderne. Nouvelle Édition. Vol. 32, Paris-Leipzig: Chez Madame C. Desplaces-Librairie; s.a., p. 659-661; sobre el sujeto de mi estudio, véase además: Davenport, Richard A. A Dictionary of Biography. London: Thomas Tegg; 1831, p. 458.

31. Además de esta edición de lujo se hizo una segunda en tamaño octavo en siete volúmenes (1788-1824). Findley, Carter Vaughn. Presenting the Ottomans to Europe: Mouradgea d'Ohsson and his «Tableau général de l'Empire Ottoman». Stockholm: Swedish Research Institute in Istanbul; 2003. Sobre los d'Ohsson, Ignatius y Constantin, vése: BIOGRAPHIE Universelle, n. 30, vol. 29, p. 471-473. 
una mujer, aparece encadenada y esclavizada por el turco, en D'Ohsson se muestra a Mahoma como un sabio legislador del Islam ${ }^{32}$.

Como el conocimiento directo de los turcos de Constantinopla, y en general de la Sublime Puerta, era prácticamente imposible, lo habitual en los viajeros fue observar algún individuo, y de lo que se veía concluir que todos los demás habitantes de la ciudad eran iguales, sin ningún matiz.

Curioso, culto y atento observador, el británico John Cam Hobhouse recurrió a la historia para explicar el «ser» del otomano y, también, la situación de la mujer en dicha sociedad. La tesis principal que mantuvo fue que existía una solución de continuidad en muchas prácticas culturales entre Oriente y Occidente, y para demostrarla Hobhouse ofreció una serie de ejemplos sobre improntas comunes a los bizantinos y otomanos. Durante la existencia de Bizancio ir a caballo era un signo de dignidad, y estaba vetado a los judíos, salvo al primer médico del Sultán; los osmanlíes mantuvieron esta costumbre, aunque en ellos el origen de esta tradición procedía de los tártaros y no de los griegos. Lo mismo podría decirse de la barba, común entre los griegos y desconocida por los turcos hasta que la adaptaron tras la conquista de Constantinopla en 1453 por un fenómeno de mimetismo. Existía pues un sustrato común de pautas culturales que era universal en todos los pueblos, pero que, según Hobhouse, la religión, las leyes y el azar habían matizado en el curso del tiempo ${ }^{33}$. Por esta razón, los rusos, los polacos y los húngaros, aún siendo cristianos como el resto de los europeos, por su origen oriental conservaban todavía atavismos que no existían entre los occidentales. Los otomanos, pues, eran culturalmente los continuadores de las tradiciones que habían sido comunes también al mundo clásico greco-romano ${ }^{34}$.

Lo que la mayoría de los textos de la época muestran de forma evidente, pues, es un cambio de actitud hacia el mundo otomano a lo largo de la Ilustración. Frente a la homogeneidad racial, que no religiosa, de los países europeos occidentales, el Imperio Otomano era diverso, pues además de los turcos vivían en sus dominios una gran variedad de pueblos que practicaban un amplio abanico de creencias religiosas. Si hasta finales del último

\footnotetext{
32. Findley, n. 31, p. 64.

33. Hobhouse, John Cam. Travels in Albania and other provinces of Turkey in 1809 and 1810. Vol. II, London: John Cawthorn; 1818, p. 206-211.

34. «Los turcos tienen un poco de griegos y mucho de romanos». Idea apuntada también en D'Irumberry, n. 6, p. 157-158.
} 
cuarto del siglo XVIII los occidentales sienten curiosidad por los turcos, que se manifiesta en el énfasis en dar cuenta de sus diversiones, modo de vestir, descripción de los restos antiguos, estilos de vida de los diferentes grupos, etc. - aunque en prácticamente casi todos los visitantes se dio un rechazo generalizado hacia el Islam como una religión equivocada ${ }^{35}-$ de forma creciente en los últimos años de esa centuria, y ya claramente en la siguiente, la simpatía se tornó en un claro rechazo hacia el sistema político otomano, al que se consideró despótico, opresor, decadente y que subyugaba a las minorías que habitaban en los territorios del Imperio, especialmente los griegos. Me parece muy significativo el hecho de que salvo algunas excepciones, como Lady Mary Wortley Montagu (1689-1762), prácticamente desde el siglo XVII casi todos los viajeros advirtieran despotismo y opresión hacia la mujer otomana, mientras que en relación con los varones sus juicios fueran más benévolos y animados por una sana curiosidad. Sin embargo, a fines del XVIII todos están oprimidos, varones y mujeres, ellas doblemente, por razón de su sexo y por el dominio político y arbitrario que padecían todos los vasallos de Estambul.

La creciente debilidad política y militar de la Sublime Puerta motivó en buena medida ese cambio de actitud, más aún tras las pérdidas territoriales al concluir las guerras con Rusia que, definitivamente, pusieron en evidencia la impotencia de Estambul y la necesidad de ser apoyada por las potencias occidentales ${ }^{36}$.

Las conclusiones del británico William Eton (fl. 1798), fueron resultado de muchos años de observación rigurosa y objetiva, y de un buen conocimiento del idioma. Veinte años de cónsul en el Imperio le daban suficiente autoridad para ofrecer un panorama objetivo del mismo. Para Eton el peor retrato que se podía ofrecer de los turcos era el que ellos mismos se habían dibujado: inhumanos, injustos, incivilizados y descuidados en su relación

35. «De todas las Religiones falsas la Mahometana es la más peligrosa, pues además de halagar los sentidos tiene muchos puntos en común con el Cristianismo». Pococke, Richard. Voyages de... en Orient, dans l'Egypte, I'Arabie, la Palestine, la Syrie, la Grèce, la Thrace, etc., vol. Vl, Paris: Chez J. P. Costard; 1772, p. 23.

36. Cuenta Pouqueville que los turcos que vivían en la parte europea de Constantinopla se pasaban las horas mirando la otra orilla, en la que solían tener enterrados a sus familiares. Esas largas horas de contemplación de Oriente respondían a la creencia de que la parte asiática sería el refugio de los osmanlíes «cuando una nación de hombres rubios les expulsaría de Europa». Pouqueville, François Charles Hugues Laurent (1805). Voyage en Morée, à Constantinople, en Albanie. Vol. II, Paris: Gabon et Cie.; 1805, p. 117. 
con las provincias del Imperio, lo que había producido el abandono del campo y su despoblamiento. La liberación de los griegos, sometidos al poder de Constantinopla, era una necesidad imperiosa, pues era la única minoría con un pasado glorioso y occidental que podría independizarse de las arbitrariedades de los osmanlíes ${ }^{37}$.

\section{La contribución de Pedro María González al conocimiento del turco: entre el saber libresco y un atento empirismo}

Ya he adelantado que González se informó en otras fuentes de su tiempo acerca de los hábitos y costumbres de los turcos. El criterio de autoridad fue determinante a la hora de seleccionar sus fuentes que, como acabo de indicar, en su mayor parte ofrecían una imagen distorsionada del mundo osmanlí. Sin embargo, cuando González observó de primera mano a los habitantes de Esmirna y pudo entablar relación personal con ellos, el retrato que ofreció de los mismos fue muy enriquecedor. Esmirna no era una ciudad tan espectacular como Constantinopla desde el punto de vista monumental, por lo que pudo buscar otros elementos que justificaran una nueva obra sobre las ciudades turcas de la época. La cuidadosa descripción de los varios grupos étnicos y religiosos que convivían en Esmirna, a veces con fuertes tensiones entre sí, justificaba con creces un escrito de estas características. Y a esa tarea se dedicó con denuedo. Precisamente, los acontecimientos que vivió de primera mano - como una rebelión de los jenízaros en la primavera de 1797- y que plasmó en su manuscrito son los más interesantes y ajustados.

Aristizábal, Solano Ortiz de Rozas y los demás españoles se reencontraron con Constantinopla, pero González se encontró con Esmirna, una ciudad desconocida por los españoles y de la que no existían crónicas ni informes previos, salvo las de los visitantes de origen francés. El único autor que con anterioridad a González había hecho de Esmirna destino final de su viaje, Antoine Galland (1645-1715), escribió una obra que no conoció impresión hasta más de trescientos años después ${ }^{38}$. Por otro lado, Paul Rycaut, por muchos años cónsul de la Corona británica en esa ciudad, no

37. Eton, n. 15, vol. I, p. III-XIX y 1-7.

38. Galland, Antoine. Le Voyage à Smyrne. Un manuscrit d’Antoine Galland (1678). Paris: Editions Chandeigne; 2000. 
dejó ningún volumen dedicado monográficamente a la misma, aunque sí una importante correspondencia ${ }^{39}$. Por ello, González buscó otras fuentes que le hablaran de Esmirna, como Joseph de la Porte o Joseph Pitton de Tournefort, y que le informaran de aspectos generales sobre los ciudadanos del Imperio, incluidos los europeos residentes en la ciudad, los francos.

En 1796 Esmirna contaba con aproximadamente 130.000 habitantes «y hasta 150.000 si se computan los extranjeros», de los cuales aproximadamente 86.000 eran turcos, 35.000 griegos, 5.000 armenios y 4.000 judíos ${ }^{40}$. González ofreció información precisa articulada sobre la base de las prácticas religiosas ligadas al nacimiento, los esponsales y los ritos mortuorios de cada millet, una sistemática que ya había sido utilizada por otros viajeros ${ }^{41}$. De la mayoría de estos millets González dio una información mayormente libresca, más comprensiva con los de religión cristiana que con el resto. Sin embargo, de los sefardíes, los únicos con los que pudo trabar una relación más íntima por razón del idioma, dio detalles muy interesantes sobre sus usos y costumbres. Me centraré, pues, en los comentarios de González acerca de los judíos de Esmirna.

A decir del sevillano la comunidad judía de Esmirna tendía a «disminuir porque no se renuevan como hacen los demás habitantes de la Ciudad con los nuevos colonos que vienen a establecerse en ella con frecuencia». Originarios de las ciudades más próximas, de Trípoli y Túnez, crecieron con la llegada de naturales de los Salónica y, más tarde, de marranos de la Península Ibérica. La actitud de González hacia esta minoría fue de clara crítica, pero al mismo de tiempo de admiración por su capacidad comercial y de hacer negocios. Hay, pues, un dualismo bastante común en los españoles que tuvieron relación con los hebreos otomanos, de acercamiento y rechazo. Como ha señalado Martín Asuero, una mezcla de «prejuicios y realidad» ${ }^{42}$.

Su lengua mayoritaria era el español antiguo, judeo-español, o ladino, con muchas voces portuguesas y otras extranjeras. Otro dato que hablaba a favor de su pasado peninsular era la frecuencia de apellidos españoles

39. Esta correspondencia ha sido utilizada muy inteligentemente por Sonia Anderson en su monografía dedicada a Rycaut. An English Consul in Turkey. Paul Rycaut at Smyrna. 1667-1678. Oxford: Clarendon Press; 2001.

40. González, n. 5, vol. I, p. 100.

41. Tal es, por ejemplo, la tónica seguida por Galland, Tournefort, Guer y otros tantos; y entre los españoles, por Moreno y Solano Ortiz de Rozas.

42. Martín Asuero, Pablo. Antonio de Zayas y los judíos Otomanos. Raíces. 1997; 11: 61-64. 
entre ellos, cuestión que obviamente le llamó la atención al gaditano. Pero a pesar de que por siglos habían mantenido el español como lengua de comunicación, esta circunstancia no fue muy valorada por González, pues según él su castellano había perdido «toda la belleza y armonía del (...) antiguo».

El mehalle, o barrio judío, estaba situado en la parte alta de la ciudad, al igual que el de los musulmanes, mientras que los armenios, griegos y europeos habitaban en las cercanías del puerto, próximos a la Estrada de los Francos, el nervio comercial de Esmirna. Salvo los europeos, que tenían una intensa vida social, los otros millets vivían muy enclaustrados en sus barrios, y tan sólo la activa vida económica del muelle de Esmirna permitía romper parcialmente la incomunicación entre los diferentes grupos.

Una proporción notable de los individuos de la comunidad judía se dedicaba a los negocios. Para Tournefort su importancia comercial en la ciudad era absoluta: «todo el comercio se hace por medio de los judíos; todo lo que se compra o vende pasa por sus manos» ${ }^{43}$. Por esta razón los hebreos de Esmirna vivían «muy holgadamente».

Un miembro de la familia de los Arditi, emparentada con los Soncino, tenía en exclusiva la Aduana de los Francos, uno de los ejes centrales del comercio portuario. Poseían, además, dos o tres casas comerciales potentes y varias más de menor peso económico. Tenían un ganado prestigio como corredores de comercio, y también eran cotizados como dragomanes. Otras actividades, mayoritariamente artesanales, tampoco les eran extrañas. Por ejemplo, la preparación de lanas, como la de tiftik, que la trabajaban de diversos modos según el gusto del comprador.

La comunidad hebrea repartía proporcionalmente entre sus miembros y en función de sus bienes una cantidad a abonar al Sultán, hasta llegar a las 15.000 piastras, que era la suma comprometida como impuesto ante las autoridades de la ciudad, y que cobraban seis de los doce Diputados de la Comunidad. Además se debía de sostener a los rabinos, a los pobres de solemnidad y a los enfermos, a los que no se les privaba de nada. Con cierto asombro González comenta la anécdota de un enfermo que, por su deseo, fue acompañado «por una orquesta pagada por la Comunidad Judaica para divertirle cuatro horas diarias». Esta ambigua actitud de admiración y desprecio hacia los judíos se muestra muy diáfana ante esta anécdota,

43. Tournefort n. 8, vol. II, p. 498. 
sobre la cual el sevillano escribió en su manuscrito: «sin embargo los judíos, aquella nación inicua, aborrecida y justamente detestable, nos dan en esta parte lecciones dignas de aprecio y de imitación».

La vida religiosa de los hebreos giraba en torno a tres acontecimientos básicos en la vida individual. La circuncisión de los varones, los esponsales y la muerte. La primera obligatoriamente tenía lugar el día octavo del nacimiento de un varón. No era necesaria su ejecución por un rabino ni tampoco su presencia. Toda persona que conociera la técnica estaba capacitada. Era motivo de fiesta y regocijo entre los parientes y amigos, «la música, la danza, las colaciones y refrescos acompañan y terminan la celebración de la circuncisión».

Las bodas solían ser por arreglo entre familias, mediante contrato $-k e$ tubah-, y los novios tenían absolutamente prohibido bajo multa encontrarse hasta seis días antes de los esponsales. Ese día, acompañado de familiares y amigos, estaba autorizado el varón a visitar a su novia, y si era de su agrado los acompañantes le ofrecían un regalo en prueba de conformidad. Cuatro días después se repetía la visita y entonces el novio entregaba a la mujer un anillo de oro, con lo cual ya estaba autorizada a salir de casa. Ese día, o al siguiente, se rubricaba el contrato matrimonial que estipulaba la dote de la novia, la mitad de la cual pasaba al varón.

Quizás por el hecho de que González fuera invitado a una boda de un judío rico, su descripción de la misma es de un realismo y vivacidad muy interesantes. En la madrugada del día de la ceremonia la novia, que apenas tenía nueve años, salió de casa de sus padres adornada con sus mejores galas, «cubierta de un velo de gasa blanca y acompañada de parientes y amigos». Delante iban los criados con antorchas encendidas y un coro «de judíos y judías cantando y bailando al son de sus panderos». Su madre y la del novio la sentaron en un dosel de papel pintado, y así permaneció, silenciosa y con la vista fija en el suelo, hasta la diez de la mañana. Mientras, los convidados esperaban en salas separadas según su sexo. Delante del dosel donde estaba sentada la novia colocaron una mesa con muchos candelabros encendidos.

A las nueve de la mañana se presentaron dos rabinos, uno de los cuales leyó en voz alta las cláusulas del contrato «en una especie de canto muy semejante al polo de los gitanos». Al finalizar la lectura el rabino se acercó a donde se hallaba el novio y, tras firmar éste el documento, lo acompañó hasta el dosel (jupá) y lo situó a la izquierda de la novia. Una vez cubiertas las cabezas de ambos con una «muselina blanca, ancha como una toalla», 
hizo beber a los dos el vino de una copa, con lo cual concluyó la ceremonia. Los festejos duraron ocho días, en los cuales el cante el baile y la comida estuvieron presentes de continuo. Los recién casados consumaron el matrimonio una vez, y en los siguientes quince días se abstuvieron totalmente, al objeto de purificarse. La novia permaneció durante esas dos semanas guardada por dos mujeres, que comían y dormían con ella.

Cuando un judío fallecía era norma enterrarlo inmediatamente. El cadáver era lavado cuidadosamente, amortajado con un lienzo de lino blanco y enterrado sin caja. Al cabo de un tiempo se colocaba una losa de mármol en el lugar donde estaban los restos del difunto, y en ella se grababa el nombre «día y año de fallecimiento, sus circunstancias y edad, empleo público y la consideración que gozaba entre los suyos, sin olvidar los instrumentos de su oficio o profesión». Durante los siguientes siete días los familiares no salían de casa, los varones no se rasuraban la cabeza en treinta días, y una vez al año acudían al cementerio. Dada la variada procedencia de los miembros de este colectivo, las leyendas de las lápidas estaban escritas en un sinfín de idiomas, como hebreo, griego, turco y español. Cuenta González que

«en una de ellas leí, con mucha sorpresa por la hermosura del carácter y la propiedad del lenguaje, Aquí yace el malogrado David Vicino, falleció día viernes».

De todos los habitantes de Esmirna los griegos y judíos eran, según González, los más dados a las diversiones. El jornal ganado en el curso de la semana lo dedicaban los hebreos para su solaz y entretenimiento en los días no laborables. Sus festejos eran ruidosos, pero sin molestar a los vecinos. Aficionados a los juegos de cartas, apostaban grandes sumas. Las mujeres también eran «amigas de las diversiones, aficionadas a los licores fuertes, y fuman de continuo como los hombres y en las mismas pipas». Pero eran «desairadas, sucias, y de facciones abultadas, aunque bellas; por lo general son muy blancas y de tez fina y delicada». Cualquier acontecimiento familiar era idóneo para organizar un festejo, con bailes y cantos. En las bodas gastaban sin freno y si era preciso acudían a prestamistas para dar más relieve al acontecimiento. También festejaban las grandes festividades religiosas, como la de «las Cabañas o Tabernáculos, (que) dura quince días en conmemoración de la peregrinación por el desierto; durante esta festividad todo es bailes, convites y diversión en 
el barrio de los Judíos; ninguno de ellos trabaja en estos días y todos se acuestan, precisamente, debajo de toldos, que ponen para aquel efecto en los patios, jardines, o terrazas».

González apenas mostró interés por las semejanzas culturales entre los otomanos y los hispanos. Sin embargo, dio cuenta de una, concretamente las bendiciones que el rabino ofreció al término de la ceremonia nupcial, que equiparó con el castizo canto del «polo de los gitanos».

\section{Conclusión}

Aunque Esmirna no gozó de tanto favor y atención por los viajeros, la reivindicación de su pertenencia al Occidente cristiano y clásico también fue muy ostensible en algunos de ellos. Por ejemplo, en la vista panorámica que Tournefort ofreció de la ciudad en el segundo volumen de su Voyage au Levant (1717), tres son los únicos elementos que destaca y nombra en la lámina: la ciudadela, es decir, el castillo del Monte Pagos, de construcción anterior a la llegada de los turcos a la ciudad, las «Ruinas del Teatro» de la época clásica, y la «Iglesia de San Policarpo», el primer mártir cristiano de la Esmirna antigua, además de la presencia de las abundantes banderas europeas desplegada en las naves atracadas en su puerto y en alguna de las residencias consulares de la Estrada de los Francos, es decir, clasicismo, cristiandad y colonización comercial, como señas de identidad del pasado glorioso y del dinamismo presente y futuro de la ciudad, cuyos restantes elementos quedaban desdibujados y englobados en ese trípode.

Tan europea occidental consideró González a Esmirna que de las viviendas que la componían González prestó la mayor atención a las residencias de verano de los francos, como en general hicieron otros forasteros en este puerto de Anatolia. No deja de ser llamativo que otros transeúntes, como el inglés John Cam Hobhouse, cuando vio la estructura urbana de Esmirna le vino enseguida a la mente las ciudades de Andalucía que había conocido en 1809, mientras que González, sevillano y afincado en Cádiz, no supo apreciar este significativo detalle. Sólo notó la suciedad y estrechura de las calles y la mala calidad de la construcción de las casas. Las residencias de verano de los francos, ubicadas en aldeas de la periferia, convertían a estos villorrios en lugares plenamente occidentales, al igual que la Estrada de los Francos lo era en la misma ciudad de Esmirna. Esa necesidad por parte de González de mostrar la cultura otomana como algo totalmente extraño 
a la tradición, los valores y las costumbres españolas le llevó a ignorar, también, que el juego del cirit, una de las diversiones de mayor aceptación entre los turcos, era igual en su ejecución y normas que el castizo juego de cañas, que se practicaba en nuestro país ya desde época medieval, y que estuvo vigente hasta principios del siglo XVIII. Una vez más un inglés, John Cam Hobhouse, al igual que había encontrado puntos de encuentro entre la geografía urbana de Esmirna y las ciudades andaluzas, volvió a poner en evidencia esa nueva semejanza entre esas dos diversiones, la otomana y la española ${ }^{44}$. Finalmente, los baños públicos, o haman, tenían también su correlato en la tradición cultural española de la época islámica, detalle que tampoco supo advertir González. No se olvide que muchas ciudades españolas se llaman Alhama, palabra que deriva precisamente del término árabe haman. Obviamente, al ignorar esos parecidos culturales, González se situaba aparentemente en una posición distante, lo que le permitía recalcar los elementos más negativos de la cultura y de las tradiciones osmanlíes, o bien analizarlas desde la curiosidad, en la medida en que eran a sus ojos totalmente nuevas. Unos ojos occidentales que disecaban la cultura turca desde las normas morales de las potencias europeas, sin considerar que otras culturas, como la turca, tenían también sus valores, los cuales eran el resultado de un proceso histórico propio. Pero cuando era manifiesto que existían elementos comunes con nuestro pasado histórico, como el ladino de los judíos, González adoptó una actitud paternalista y de crítica. El español de los hebreos de Esmirna apenas guardaba relación con el de sus antepasados hispanos, pues su expulsión en 1492 supuso el comienzo de una pérdida y corrupción de su idioma materno ${ }^{45}$.

Desde los valores morales occidentales, en general todos los viajeros juzgaron negativamente algunas costumbres arraigadas en los dominios

44. Hobhouse, n. 33, vol. II, p. 45-46.

45. También Tournefort encontró referentes de la cultura otomana en España, pues antes de este viaje había estado en Andalucía y conocido de primera mano algunas ciudades, especialmente Granada. Por ejemplo, comparó la belleza de los palacios de Constantinopla con La Alhambra de Granada «un prodigio de la Arquitectura, cuyo Patio de los Leones está recubierto de placas de mármol más grandes que las que hay en las tumbas de nuestras iglesias». Tournefort, n. 8, vol. I, p. 495-496. En otras dos ocasiones relacionó detalles de su viaje a Oriente con experiencias durante su estancia en España. Así confrontó la abundancia de fuentes en las casas de Prusa, la actual Bursa, en Bitinia, con las de Granada (op. cit., p. 468). En esa ciudad oyó hablar en español, en su opinión muy puro, y los judíos de esta capital le narraron que tras su partida de España habían conservado su lengua materna. Tournefort, n. 8, vol. I, p. 472. 
otomanos. Tal es el caso de la práctica del kabin, o contrato matrimonial a tiempo fijo, por una cantidad, y sancionado por la autoridad civil del lugar donde tenía lugar, al que solían recurrir los marinos que debían de permanecer mucho tiempo en tierras otomanas, o entre los mismos ciudadanos del Imperio. François Baron de Tott, por ejemplo, daba cuenta de que en las islas del Egeo, como Creta, era una práctica frecuente entre musulmanes y griegas y que, según este viajero francés, suponía además una forma de alianza cultural y política entre los diferentes grupos étnicos que vivían en los dominios de La Sublime Puerta y de ruptura de fronteras entre los diferentes grupos. Sin embargo, fue más generalizada la crítica a esta forma matrimonial por lo que de inmoral tenía a los ojos de los occidentales ${ }^{46}$. Una vez más, algunos perspicaces observadores quisieron ver semejanzas entre esta forma de desposorio y otras que aún se daban en la península ibérica. Paul Rycaut, por ejemplo, asoció el kabin con antiguas costumbres hispanas, como casarse a media carta, o estar emancipado ${ }^{47}$. 